\title{
Embodying Embodied Design Research Techniques
}

\author{
Danielle Wilde' ${ }^{1}$, Oscar Tomico ${ }^{2}$, Andrés Lucero ${ }^{1}$, Kristina Höök ${ }^{3}$, Jacob Buur ${ }^{1}$ \\ ${ }^{1}$ University of Southern Denmark \\ ${ }^{2}$ Eindhoven University of Technology, Netherlands \\ ${ }^{3} \mathrm{KTH}$, Sweden \\ \{wilde,lucero,buur\}@sdu.dk, o.tomico@tue.nl,khook@kth.se
}

\begin{abstract}
The value of engaging the full gamut of sensory motor skills in the design and use of smart objects and systems is recognized. Yet methods for arriving at robust and reliable outcomes for their development are not fully understood, nor are they easily reported or transferred through typical conference presentations and paper submissions. New forms of knowledge transfer, such as pictorials (e.g., DIS and RTD conferences), and video are enabling enhanced, image-enriched reporting of outcomes. Yet appropriate transfer of embodied research methods remains elusive.
\end{abstract}

In this workshop we propose to investigate how embodied research techniques may be used as direct and unmediated vehicles for their own reporting. Rather than engaging in oral presentations, participants will lead other participants through a proven embodied method or approach. Small groups will create mash-ups of techniques, exploring ways that the new approaches might coherently be reported. Participants will be encouraged to experiment with different recording techniques, including body-mounted sensing and recording devices, as well as less conventional approaches. The intention is to find appropriate ways of reporting embodied experiments, so that intangible elements are not lost. Participants will be supported to reflect on unfolding discoveries, to share impressions, as well as outcomes, including documentation experiments that aim to tangibly capture and communicate the processes undertaken.

Embodied ideation, communication and collaboration techniques enable enhanced creative engagement and assist creativity [2]. By applying such methods to the problem of their reporting, we hope to deepen understanding of how to move towards enriched, nuanced and repeatable methods for embodied design and knowledge transfer. Crucially, our intention is not simply to find the next form of research reporting. Rather, this workshop will engage participants in an experimental enquiry, so that embodied design research may become an active area of inquiry moving forward.

Copyright $(\mathrm{C} 2015$ is held by the author(s). Publication rights licensed to Aarhus University and ACM

5th Decennial Aarhus Conference on Critical Alternatives

August 17-21, 2015, Aarhus Denmark

DOI: http://dx.doi.org/10.7146/aahcc.v1i1.21620

\section{Author Keywords}

Embodied design; embodied ideation; embodied interaction; research processes; reporting methods; wearable technology; video capture; quantified self

\section{ACM Classification Keywords}

H.5.m. Information interfaces and presentation (e.g., HCI): Miscellaneous.

\section{INTRODUCTION}

Embodied interaction continues to gain currency. Yet reporting of methods and techniques used in embodied research generation remains a challenge. Conferences (e.g., $\mathrm{TEI}^{1}$ ), special journal issues (e.g., $[15,23]$ ) and doctoral theses (e.g., $[14,13,25])$ are devoted to the subject. Yet embodied methods are not readily communicated through the written or spoken word. New forms of knowledge transfer, such as pictorials (e.g., at DIS $2014^{2}$ and RTD $2015^{3}$ conferences), and video are enabling enhanced, image-enriched reporting of outcomes. Yet appropriate transfer of embodied research methods remains elusive.

Our workshop is an experiment with how to engage, reflect on, document and report embodied design research methods and techniques, to find new opportunities for development, cross-fertilization, collaboration and effective knowledge transfer as interaction techniques and methods develop. Our intention is not simply to find the next form of research reporting. Rather, we recognize that over the coming decennial radical changes to how research is undertaken may occur. By laying the foundation for coherent and rich exchange of embodied ideation methods, we hope to simultaneously contribute to understanding of how to effectively share them, and to the evolution of these methods. By engaging participants in an experimental enquiry into embodied research reporting, we intend this area to become an active area of inquiry moving forward.

\section{A Panoply of Approaches}

Embodied interaction plays out in many different ways, bringing together and bridging different disciplines and approaches. Some researchers use the body and movement as material. Wilde, Thecla Schiphorst and Sietske Klooster, for example, meld performing arts and interaction

\footnotetext{
${ }^{1} \mathrm{http}: / /$ www.tei-conf.org

$2 \mathrm{http}: / /$ dis2014.iat.sfu.ca/index.php/pictorials/

${ }^{3} \mathrm{http}: / / w w w . r e s e a r c h t h r o u g h d e s i g n . o r g /$ submissions/
} 


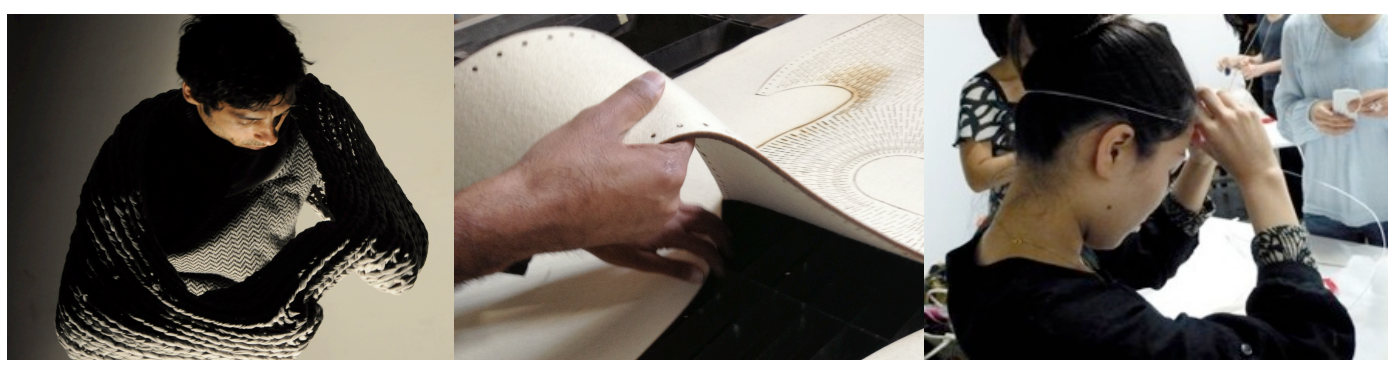

Figure 1: (a+b) Close to the Body, IAAC Research Studio http://www.iaac.net/interaction/program-2researchstudios.html; (c) Thinking-though-making OWL Circle: http://daniellewilde.com/body-tech-poetics/circles/

techniques in design choreographies to develop portable and wearable outcomes [26]. Höök and colleagues at Mobile Life, SICS and KTH use Mindfulness and Somaesthetics [20] to develop theories and practices around core mechanics and experiential artefacts (e.g., [22]). Susan Kozel develops improvisational methods using dance and phenomenology to design for intimacy $[6,11,12]$; Kristina Andersen [18], and Greg Corness [3], with Schiphorst, have used performance-based methods and performer technique to bring focus to the knowing body. Buur and colleagues engage the body through Object Theatre and improvisation [2], and use a range of video documentation and editing techniques to capture and communicate emerging research outcomes in the wild [27]. Johan Stjernholm [19] looks at relations between the processes of creating, performing, and perceiving aesthetic embodied practices with digital media. David Kirsh [10] explores the question of physical thinking, using the body as an instrument of cognition, and Phillip Ross [16] uses aesthetic experience as a core mechanism for design.

Other researchers focus on developing movement skills. Caroline Hummels, Kees Overbeeke and Klooster [7], for example, have long championed the need for the designer as movement expert, foregrounding the expressive power of gesture. Tom Djajadiningrat, Ben Matthews and Marcelle Stienstra [4] stress the importance of skilled action when designing interaction, bringing focus to the experience of use. Yet others focus on designing representations of movement, evaluating the user experience, mapping interactions, or exploring sensing technologies [13]. For example; Seçil Uğur [24] designed garments that can communicate the emotions of the wearer as dynamic tangible interfaces and extensions of the human body; and Eunjeong Jeon, with Touch Me, Feel Me, Play with $\mathrm{Me}$ [8], created dynamic tactile experiences that invite participants to interact for comfort.

Despite, or perhaps because of this breadth and diversity of practice, a major challenge remains: coherency of communication. Typical avenues for reporting do not readily encompass the multiplicity of perspectives or the embodied nature of relevant research methods and techniques. Workshops provide an important, yet ephemeral forum through which to share methodologies (e.g., $\left.\mathrm{MOCO}^{4},[19]\right)$. Yet the conundrum of how to tangibly and robustly transfer knowledge, over time, in ways coherent with the richness of embodied methods and experiences, remains unsolved.

As embodied methods are increasingly leveraged in research, this challenge will only become more pressing. In a call to the community to recognize and respond through action to this shared challenge, this workshop will bring together concerned participants, in the hope that together we may move towards coherent solutions.

\section{WORKSHOP PLAN}

Over a single day we will engage up to 15 participants in an embodied interrogation of the key issues related to knowledge transfer and reporting of embodied research methods and techniques. During the first half of the day, each participant will lead others in an embodied experience of a proven research method or technique - enabling the participants to experience by doing, thus allowing for direct embodied experience of methodologies. The second half of the day will focus on actively shifting and merging the methods and techniques experienced in the morning session, and experimenting with novel approaches to documenting and reporting. This will be done by combining approaches / mixing / melding / mashing up in small groups, and making use of novel capture methods.

To facilitate documentation and capture, we will provide a number of capture and sensing devices. We will also request participants come prepared with material, equipment or approaches they feel may contribute to the experiment. Groups will be fluid - participants able to leave or join a new group at any time. This will enable ideas to merge and groups to form in an instinctive and discretionary manner. The structure of this part of the workshop will draw on the strengths of improvisation in contributing to idea generation and development [9]. In musical improvisation, for example, knowing where to go next becomes a series of small decisions made in a hyper aware state of flow in which the musician "knows" both the minds and desires of his or her fellow musicians, and also holds the experience of the audience as an almost physical

$4 \quad$ http://moco.ircam.fr, http://moco.iat.sfu.ca 


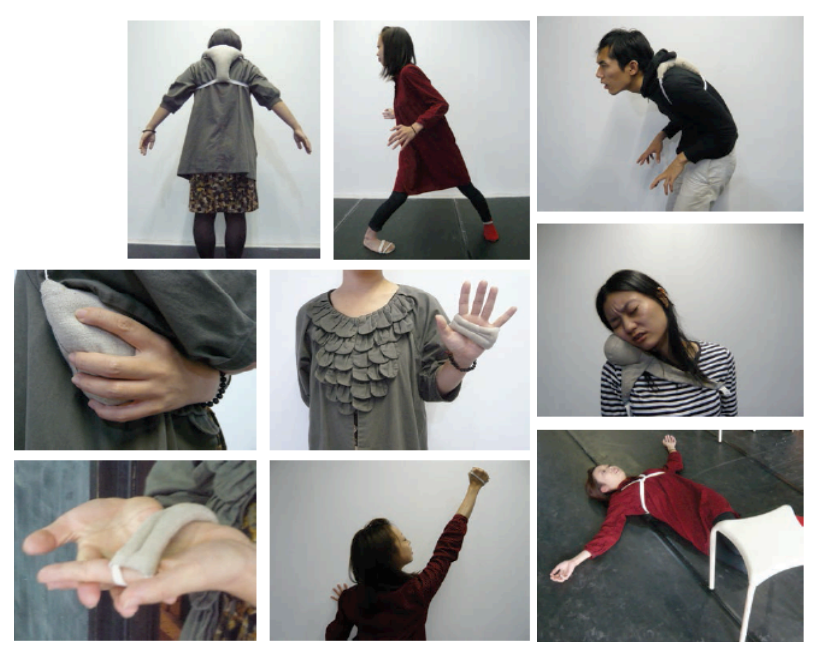

Figure 2: Dancers imagining yet-to-be-imagined technologies From the OWL interviews: http://ow.ly/QaKde

"thing" which can be examined, turned, changed, and at some point is "done" [17]. Turning this approach onto the challenge of sharing and documenting embodied design research techniques, will enable us to use the techniques themselves as a anchors, or guides. This approach has been leveraged previously in embodied idea generation [25], and is well suited to the challenge we are confronting.

Participants will be encouraged to experiment with different recording techniques, throughout, including bodymounted sensing and recording devices, as well as less conventional approaches. The intention will be to find appropriate ways of capturing and reporting embodied experiences and experiments, so that the intangible elements are not lost. At the end of the day, the workshop participants will regroup to reflect on what happened and share impressions, as well as outcomes, including documentation experiments that aim to tangibly capture and communicate the processes undertaken. In the spirit of an ongoing conversation, we are not looking for definitive answers. Rather we recognize that over the coming decennial radical changes to how research is undertaken may occur. By laying the foundation for coherent exchange of embodied ideation methods, we hope to simultaneously contribute to understanding of how to Alternate methods for sharing will be discussed during the workshop and actioned accordingly effectively share them, and the evolution of those methods. Outcomes will be posted on the workshop website.

\section{ORGANISERS}

Danielle Wilde is associate professor of Research at the University of Southern Denmark, Kolding. Her research focuses on embodied creativity, wearable futures and convergence - drawing on textile crafts, the performing arts, embodied interaction and scientific innovation to investigate the future of wearable and worn technologies.

Oscar Tomico is assistant professor in the Designing Quality in Interaction Research Group, and Wearable

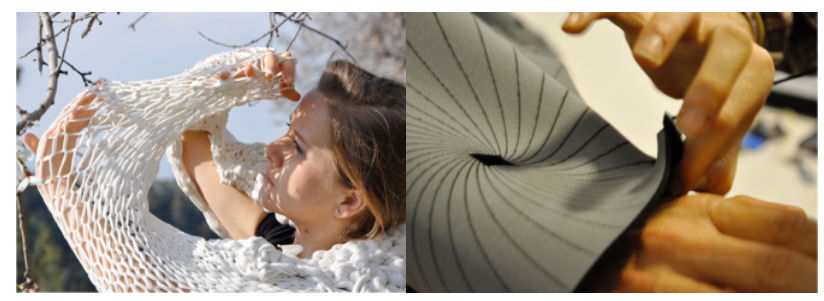

Figure 3: using the body, materials and movement to develop interfaces that invite and respond to embodied interactions. From Close to the Body: http://ow.ly/QaR1O

Senses at Eindhoven University of Technology. Projects focus on the textile industry, involving stakeholders during the design process to foster cooperation and reflective practices between participants, frame the design space, collaboration space and reformulate the design opportunity.

Andrés Lucero, is associate professor of interaction design at the University of Southern Denmark, Kolding. His focus is on the design and evaluation of novel interaction techniques for wearables. $\mathrm{He}$ recently co-organized workshops on 'Interactive City Lighting' and 'Organic Experiences' at CHI '13; 'Embarrassing Interactions' and 'Mobile Collocated Interactions' at CHI '15.

Kristina Höök is professor in Interaction Design at KTH Royal Institute of Technology, SICS, Swedish Institute of Computer Science, and director of the Mobile Life centre. She is known for her work on social navigation, seamfulness, mobile services, affective interaction and designing for bodily engagement in interaction through somaesthetics. Her competence lies in interaction design and user studies helping to form design.

Jacob Buur - is professor of Design Innovation in the Mads Clausen Institute for Product Innovation, and head of research at the University of Southern Denmark (SDU)'s Design Initiative in Kolding. $\mathrm{He}$ is an internationally acknowledged pioneer on working with video for usercentered design purposes, with experience in academia and industry. Before joining SDU he was manager of the Danfoss User Centered Design group.

\section{RECRUITMENT STRATEGY}

The call is open to parties with an interest in the design and application of embodied research processes, as well as those with expertise in analysis and recording, and strong ideas about how they might contribute to the capture and knowledge transfer of embodied research ideation techniques.

By drawing together practitioners with varying experience and expertise, we aim to develop a robust and rich community of practitioners. Criteria for selection will include quality and uniqueness of the research approach, as well as creativity of thinking around how to extend current capture, and reporting of embodied research techniques. By searching for diversity and extremes, we aim to arrive at a vital representation of this emerging, radical and dynamic field, and also to disrupt currently held assumptions. 

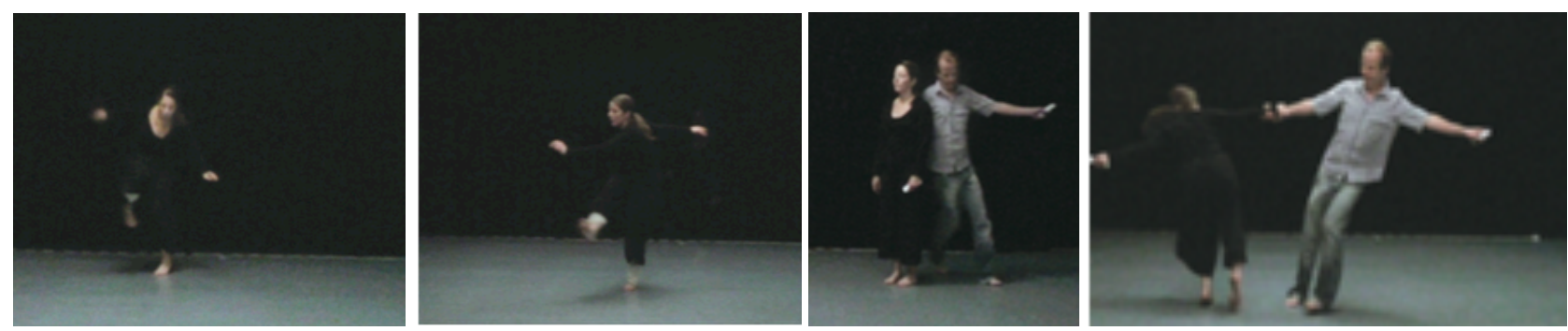

Figure 4: video stills of movement|sound coupling experiments for real-time embodied composition and performance [1]

\section{REFERENCES}

1. Bencina, R., Wilde, D., Langley, S. Gesture $\approx$ Sound Experiments: Process and Mappings Proc. NIME 2008, ACM Press (2008).

2. Buur, J., Torguet, R. Ethnographic Findings in the Organizational Theatre. Proc. EPIC 2013.

3. Corness, G. \& Schiphorst, T. Performing with a system's intention: embodied cues in performer-system interaction. Proc. C\&C 2013, ACM (2013), 156-164

4. Djajadiningrat, T., Matthews, B., and Stienstra, M. Easy doesn't do it: skill and expression in tangible aesthetics. Pers. \& Ubiq. 11, 8 (2007), 657-676.

5. Gallagher, S. How The Body Shapes the Mind. Clarendon Press, Oxford, UK, 2005

6. Hansen, L.K. \& Kozel, S. Embodied imagination: a hybrid method of designing for intimacy. Digital Creativity, 18(4) (2007), 207-220.

7. Hummels, C., Overbeeke, C. J. and Klooster, S. Move to get moved: a search for methods, tools and knowledge to design for expressive and rich movement-based interaction. Pers. \& Ubiq. 11, 8 (2007), 677-690.

8. Jeon, E. 'Enriched Aesthetic Interaction' through sense from haptic visuality. Proc. IDA Congress Education Conference (2011), 28-35.

9. Johnstone, K., Impro: Improvisation and the Theatre. Routledge, 1987

10. Kirsh, D. Thinking with the Body. Proc. Cognitive Science Society (2010), 2864-2869.

11. Kozel, S. Closer: Performance, Technologies, Phenomenology. Cambridge: MIT Press, 2008

12. Kozel, S. The virtual and the physical: A phenomenological approach to performance research. In M. Biggs and H. Karlsson (Eds.) The Routledge Companion in Research in the Arts, 2010.

13. Loke, L., Robertson, T. Moving and making strange. ToCHI 20(1), Article 7, 2013

14. Moen, J. Kinaesthetic Movement Interaction. PhD diss., KTH Royal Institute of Technology, Sweden, 2006.

15.Personal \& Ubiquitous Computing Special issue on movement-based interaction 11(8), Springer, 2007.
16. Ross, P., \& Wensveen, S. (2010). Designing aesthetics of behavior in interaction: Using aesthetic experience as a mechanism for design. IJD, 4(2), 3-13, 2010.

17. Ryan, J. Knowing When, in The Vibrancy Effect ed. Chris Salter. Rotterdam: V2_Publishing, 2011.

18. Schiphorst, T. Andersen, K. Between bodies: Using experience modeling to create gestural protocols for physiological data transfer. Proc. CHI 2004 Fringe Papers. ACM Press, 2004.

19. Schiphorst, T., Sheppard, R., Loke, L., Lin, C. (2013) Beautiful Dance Moves. Proc. C\&C 2013. ACM Press, 2013.

20. Shusterman, R. Body Consciousness: A Philosophy of Mindfulness and Somaesthetics. Cambridge University Press, 2008.

21. Stjernholm, J. Moving through the virtual: A dramaturgy of choreographic practice and perception. Dance Dramaturgy: Catalyst, Perspective and Memory. Proc. Society of Dance History Scholars Conference, SDSH, 2011.

22. Sundström, P., Vaara, E., Solsona, J., Wirström, N., Lundén, M., Laaksolhati, J., Waern, A., Höök, K. (2011) Experiential Artifacts as a Design Method for Somaesthetic Service Development. Proc. 2011 ACM symposium on The role of design in UbiComp research \& practice. Ubicomp 2011, 33-36 ACM Press, 2011.

23. ToCHI Transactions on Computer Human Interaction Special issue on the theory and practice of embodied interaction. ToCHI 20(1), ACM Press, 2013.

24.Uğur, S. Wearing Embodied Emotions, A Practice Based Design Research on Wearable Technology. Springer, 2013.

25. Wilde, D. Swing That Thing : Moving to move. $\mathrm{PhD}$ Diss., Monash University \& CSIRO, Australia, 2012.

26. Wilde, D. Schiphorst, T. Klooster, S. Move to Design • Design to Move: a conversation about designing for the body. Interactions 18(4) ACM Press, 2011.

27. Ylirisku, S. P., Buur, J. Designing with Video. Springer Verlag. 2007. 